\title{
Correlates of family, school, and peer variables with adolescent substance use in Taiwan
}

\author{
Grace Hui-Min $\mathrm{Wu}^{\mathrm{a}}$, Mian-Yoon Chong ${ }^{\mathrm{b}}$, \\ Andrew T.A. Cheng ${ }^{\mathrm{c}}$, Tony Hsiu-Hsi Chen ${ }^{\mathrm{a}, \mathrm{d}, *}$ \\ anstitute of Preventive Medicine, College of Public Health, National Taiwan University, Taipei, Taiwan \\ ${ }^{\mathrm{b}}$ Department of Psychiatry, Kaohsiung Medical College, Kaohsiung, Taiwan \\ ${ }^{\mathrm{c}}$ Institute of Biomedical Sciences, Academia Sinica, Taipei, Taiwan \\ ${ }^{\mathrm{d}}$ Division of Biostatistics, College of Public Health, National Taiwan University, Taiwan
}

Available online 12 April 2007

\begin{abstract}
This study examines adolescent substance use in relation to family, peer and school factors in the context of Taiwan. Information on family characteristics, satisfaction with performance at school, and peer influence was collected using a case-control study in which a two-stage method was applied to ascertain substance use. A set of hypotheses on interrelationships of substance use (tobacco, alcohol, betel, illicit drugs) and influences were tested with a structural equation model. There was a strong negative relation between family factors and peer relationships $(p=0.005)$. Family variables played an important role in motivation and effort to study $(p=0.004)$. High motivation and effort to study $(p=0.0012)$ and good school adjustment $(p=0.078)$ led to higher satisfaction with performance at school. A significant positive association between peer relationships and deviant peer behaviour was observed $(p<0.001)$. Satisfaction with performance at school was negatively related to deviant peer behaviour $(p=0.052)$. The direct effect of deviant peer behaviour was marginally statistically significant $(p=0.011)$ and an indirect effect of family factors on substance use was statistically significant $(p=0.041)$. In conclusion, the study found that a strong family-peer relationship and family influence has a significant effect on substance use.
\end{abstract}

(C) 2007 Elsevier Ltd. All rights reserved.

Keywords: Taiwan; Adolescents; Substance use; Family influence; Latent variable; Pathway analysis

\section{Introduction}

A number of studies have addressed the impact of family characteristics, school performance, and peer relationships on adolescent substance use (Ary,

\footnotetext{
*Corresponding author. Tel.: + 886233228021 ; fax: +886223587707 .

E-mail addresses: gracewu@ntu.edu.tw (G.H.M. Wu), bmandrew@gate.sinica.edu.tw (A.T.A. Cheng), chenlin@ntu.edu.tw (T.H.H. Chen).
}

Duncan, Duncan, \& Hops, 1999; Bahr, Hoffmann, \& Yang, 2005; Beal, Ausiello, \& Perrin, 2001; Botvin, Malgady, Griffin, Scheier, \& Epstein, 1998; Callas, Flynn, \& Worden, 2004; Hops, Davis, \& Lewin, 1999; Nash, McQueen, \& Bray, 2005; Olds \& Thombs, 2001; Sutherland \& Shepherd, 2001; Swadi, 1999; Tot, Yzaici, Yazici, Metin, Bal, \& Erdem, 2004; Weinberg, Rahdert, Colliver, \& Glantz, 1998; Wright \& Fitzpatrick, 2004). However, this approach has not been applied with Chinese youth in Taiwan, in particular. 
Bronfenbrenner's theory $(1977,1979)$ speaks about the importance of multiple contexts in the lives of youth. Yet there are questions concerning the relations among these different contexts. Some research suggests that parent and peer contexts diverge while others indicate that the separation of these three contexts is associated with deviant behaviour such as substance use.

Apart from parental and peer influences, satisfaction with school performance may also play an important role in substance use. Previous researches have found that maladaptive behaviour and coercive/aggressive interaction styles that arise in the family may have a detrimental affect on relations at school and lead to poor school performance (Caspi, Bem, \& Elder, 1989; Moffitt, 1997; Patterson, 1982). However, school factors may also play an independent role in substance use. Here, we try to disentangle the effect of family variables from school factors on substance use in Taiwan youth using a structured equation model.

\section{Method}

\section{The sample}

Data used in this study were derived from the Project on Adolescent Substance use in Taiwan (PAST) (Chong, Chan, \& Cheng, 1999). The PAST aimed at the identification of risk factors for substance use for early prevention. The methodology of the study has been described in detail elsewhere (Chong et al., 1999). In brief, a total of 18 ninth grade classes were randomly selected with all their students included for the study $(N=780)$ coming from an urban, a suburban, and a rural community in northern and southern Taiwan.

\section{The identification of substance use}

The case definition for substance use in this study was any use of tobacco, alcohol, betel, and illicit drugs. A two-stage case finding method was used to ascertain substance use. Respondents were first interviewed by trained nurses and psychiatric residents with a screening questionnaire for the use of betel, tobacco, alcohol and illicit drugs. Very low cutoff points were set to include as many cases as possible: (a) at least once per week with more than one cigarette for tobacco use; (b) at least once per week with greater than two units for alcohol drinking; (c) at least once per week with at least one grain for betel nut chewing; and (d) ever use for any illicit drug.

All who were screened positive and every one-inthree among those screened negative were immediately interviewed in the second stage by nine child psychiatrist staffs with a Chinese version of the Kiddy Epidemiologic version of the Schedule for Affective Disorders and Schizophrenia (K-SADS-E) (Puig-Antich \& Chambers, 1978) for the diagnosis of substance use disorders and other psychiatric comorbid conditions according to the DSM-III-R (American Psychiatric Association, 1987). The KSADS-E is a semi-structured clinical interview to be conducted by mental health professionals for systematic assessment of both past and current episodes of mental disorders in children and adolescents (Orvaschel, Puig-Antich, Chambers, Tabrizi, \& Johnson, 1982). A Chinese version of the K-SADS-E was developed by a group of child psychiatrists in Taiwan. A section regarding betel use was included here. Questions cover current and past use of alcohol, tobacco and betel nuts, as well as frequency and quantity of substance use, i.e., examples of some items concerning drinking alcohol are: Have you ever drunk beer, wine, or liquor? How old were you when you had your first drink? How often do you usually drink? How many drinks do you have when you drink? Have you ever gotten drunk? Do you usually drink to get drunk? Do your friends and other family ever think that you were drinking too much? Have your grades fallen because of drinking? There was no time lag between the first and the second stage case finding. All the child psychiatrists were blind to the screening results from the first stage. The inter-rater reliability of the KSADS-E among the nine child psychiatrists was found to be satisfactory: kappa was 0.73 for tobacco use, 0.87 for betel use and 0.96 for alcohol use. Only the items related to substance use will be analyzed here.

A total of 81 cases with any substance use were identified. Only two of them had used illicit drugs. A case-control study design was employed with two controls for each case, randomly selected from noncases at stage two. Four out of the 81 cases and 8 out of 167 controls were excluded, because of lack of information on social variables. A total of 236 adolescents including 77 cases and 159 controls were included in the structural equation model. Cases meeting the criteria of harmful use and dependence were coded as 1 and 2, respectively, and adolescents without any substance use were coded as 0 . 


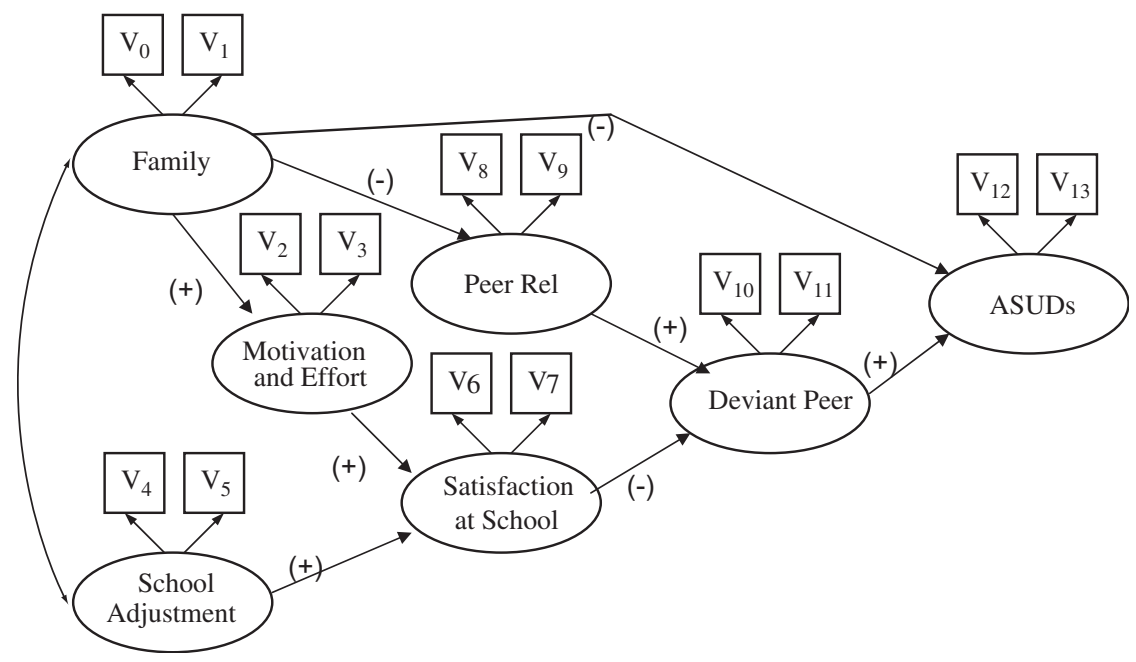

Fig. 1. Structural equation model (SEM) for pathway to ASUDs. The measured variables: $V_{0}$ : family bond; $V_{1}$ : intimate relationship between parents; $V_{2}$ : expectation of pursuing academic degree; $V_{3}$ : time spent on study after class; $V_{4}$ : class adjustment; $V_{5}$ : teacher support; $V_{6}$ : satisfaction with academic performance; $V_{7}$ : satisfaction with other relevant curriculums; $V_{8}$ : peer association; $V_{9}$ : girlfriend/ boyfriend association; $V_{10}$ : deviant behaviour at school; $V_{11}$ : harmful behaviour; $V_{12}$ : tobacco and/or alcohol use disorder; $V_{13}$ : betel nut use disorder.

\section{Measures of family characteristics, school factors and peer influence}

The manifested indicator variables within each latent variable are portrayed in Fig. 1 and detailed as follows:

\section{(a) Family interrelationship:}

The latent variable family cohesion includes two measured variables, i.e., family bond $\left(V_{0}\right)$, and intimate relationship between parents $\left(V_{1}\right)$.

Family bond was measured by four questions, including: (1) Did the students like or dislike living with parents and other close relatives; (2) Did they enjoy staying at home; (3) Did they ever think of running away from home; and (4) Did they feel loved by their parents. Each question was rated on a 1 to 4 scale with the score being a sum of ratings.

Two questions assessed the intimate relationship between parents: (1) an overall assessment of the intimacy by the respondents; and (2) did the respondent observe that his/her parents at times went out together. Ratings were from 1 to 4 , and the sum indicated the perception of an intimate relationship between parents.

(b) Academic performance and adjustment at school:

Three latent variables were included in this domain: motivation and efforts to study, school adjustment, and satisfaction with performance at school.
Motivation and efforts on study: This variable consisted of expectation of pursuing an academic degree $\left(V_{2}\right)$ and time spent on studies after class $\left(V_{3}\right)$. Expectation was measured by two questions: parental and self-expectations about the highest academic degree from junior high school to graduate studies, rated from 1 to 5 . The latter was measured by three questions: (1) average studying hours after class on weekdays; (2) average studying hours on weekends; and (3) hours spent in additional curricular courses.

School adjustment: School adjustment included class adjustment $\left(V_{4}\right)$ and teacher support $\left(V_{5}\right)$. Class adjustment was measured by the sum of scores from four items: (1) how well they got along with classmates; (2) how good was their interpersonal relationship with other classmates; (3) how well they were liked by classmates and (4) how welcome they were to play with them. Teacher support was measured by the sum of 1-4 ratings from three items: (1) how often had the respondent been praised by his/her teachers; (2) how attentive was the teacher ; and (3) how able they felt to get help from teachers.

Satisfaction with performance at school: Satisfaction with school performance was derived from satisfaction with academic performance $\left(V_{6}\right)$ and other relevant curriculum $\left(V_{7}\right)$. Each of them was assessed from the point of view of respondents themselves, and from their parents 
view (as perceived by respondents), ranging from 1 to 4 .

\section{(c) Peer influence}

Peer influence included two latent variables derived from peer relationships and deviant peer behaviour.

Peer relationships: Peer relationships were based on two indicators, peer relationships $\left(V_{8}\right)$ and girlfriend/boyfriend association $\left(V_{9}\right)$. Peer relationships $\left(V_{8}\right)$ was measured by time spent with peers in the preceding month and the number of different types of peers (in and outside school). Girlfriend/ boyfriend association was assessed by four items concerning the availability of a girlfriend/boyfriend, the frequency in attending parties with girlfriend/ boyfriend, the frequency of telephone chatting with girlfriend/boyfriend, and the number of heterosexual friends, all rated on a 1-4 scale.

Deviant peer behaviour: This latent variable refers to deviant peer behaviour, including deviant behaviour at school $\left(V_{10}\right)$ and harmful behaviour with peer group $\left(V_{11}\right)$. Deviant school behaviour includes bad language, being late for submitting homework, fighting and destruction of public property, running away from home, and missing classes. Harmful peer behaviour includes bluffing and threatening, stealing, being absent from school, going to school with arms, and joining a hooligan group. Each item was measured by the extent of involvement with peers with such a behaviour during the preceding six months on a scale ranging from 1 to 5 .

Adolescent substance use: This latent variable included two measured indicators, i.e., tobacco and/or alcohol use $\left(V_{12}\right)$ and betel use $\left(V_{13}\right)$. The use of illicit drug was not considered as a variable since only two students reported using illicit drugs.

\section{Specification of structural equation model}

According to the above observed and latent variables, we proposed the following structural equation model (Fig. 1) depicting the hypothesized association between substance use and a sequence of relations among family cohesion, motivation and effort to study, school adjustment, satisfaction with performance at school, peer relationships and deviant peer behaviour.

\section{Statistical analysis}

To assess whether measured items clustered as expected, exploratory factor analysis with orthogo- nal rotation method was first performed to check internal consistency under each latent variable. The factors came out as expected with loadings above 0.50 .

In order to test the relations between parent, school and peer variables and substance use, structural equation model analysis was performed. An exploratory step-by-step model selection was based on goodness of fit using chi-square, Bentler's Comparative Fit Index (CIF), Bentler and Bonett's non-normed index (NNFI), and the root mean square error of approximation (RMSEA).

\section{Results}

\section{Demographic characteristics}

The demographic characteristics of the adolescents were listed in Table 1. Most adolescents lived in a nuclear family, with two or fewer siblings. Almost half the parents had junior high school or less. There were no significant differences in demographic variables between substance users and non-substance users.

Table 1

Demographic characteristics of study subjects

\begin{tabular}{lrr}
\hline Variable & No. & $\%$ \\
\hline Family structure & & \\
Nuclear family & 163 & 69.1 \\
Stem family & 42 & 17.8 \\
Extended family & 21 & 8.9 \\
Other & 10 & 4.2 \\
Sibling number (the subjects are not included) & & \\
0 & 61 & 25.8 \\
1 & 70 & 29.7 \\
2 & 67 & 28.4 \\
$3+$ & 38 & 16.1 \\
Marital status of parents & & \\
Married & 210 & 89.0 \\
Separation/divorced & 15 & 6.4 \\
Widow/widower & 11 & 4.7 \\
Highest education level of parents & & \\
Elementary school or below & 63 & 26.7 \\
Junior high school & 51 & 21.6 \\
Senior high school & 71 & 30.1 \\
College or above & 51 & 21.6 \\
Family income (NTD) & & \\
$<50,000$ & & \\
50,000-79,999 & 78 & 33.1 \\
80,000-99,999 100,000 & 28 & 34.7 \\
( & 48 & 20.3 \\
\hline
\end{tabular}


Table 2

Comparison of manifested users and non-users on observed variables

\begin{tabular}{|c|c|c|c|c|}
\hline Variable & Users & Non-users & $t$-test & $p$-value \\
\hline \multicolumn{5}{|l|}{ 1. Family cohesion } \\
\hline (1) Family bond $\left(V_{0}\right)$ & 10.87 & 11.64 & 3.88 & 0.0001 \\
\hline (2) Intimate relationship between parents $\left(V_{1}\right)$ & 5.74 & 6.17 & 1.67 & 0.0967 \\
\hline \multicolumn{5}{|l|}{ 2. Motivation and effort to study } \\
\hline (1) Expectation of pursuing academic degree $\left(V_{2}\right)$ & 6.55 & 8.64 & 7.42 & $<0.0001$ \\
\hline (2) Time spent on study after class $\left(V_{3}\right)$ & 4.69 & 9.37 & 12.88 & $<0.0001$ \\
\hline \multicolumn{5}{|l|}{ 3. School adjustment } \\
\hline (1) Class adjustment $\left(V_{4}\right)$ & 12.90 & 12.98 & 0.34 & 0.7330 \\
\hline (2) Teacher support $\left(V_{5}\right)$ & 8.65 & 8.36 & -1.06 & 0.2895 \\
\hline \multicolumn{5}{|l|}{ 4. Satisfaction with performance at school } \\
\hline (1) Satisfaction with academic performance $\left(V_{6}\right)$ & 5.79 & 6.87 & 4.83 & $<0.0001$ \\
\hline (2) Satisfaction with other relevant curriculums $\left(V_{7}\right)$ & 8.25 & 8.75 & 2.34 & 0.0209 \\
\hline \multicolumn{5}{|l|}{ 5. Peer relationship } \\
\hline (1) Peer association $\left(V_{8}\right)$ & 32.05 & 9.47 & -8.58 & $<0.0001$ \\
\hline (2) Girlfriend/boyfriend association $\left(V_{9}\right)$ & 8.29 & 5.93 & -7.63 & $<0.0001$ \\
\hline \multicolumn{5}{|l|}{ 6. Deviant peer behaviour } \\
\hline (1) Deviant behaviour at school $\left(V_{10}\right)$ & 7.69 & 5.68 & -7.54 & $<0.0001$ \\
\hline (2) Harmful behaviour $\left(V_{11}\right)$ & 13.48 & 8.99 & -10.48 & $<0.0001$ \\
\hline
\end{tabular}

\section{Comparison of substance users and nonusers on observed variables}

Table 2 shows differences between substance using adolescents and non-users on observed variables. Users had weaker family bonds and had lower expectations about pursing an academic degree. Users spent less time studying and lower satisfaction with performance, but had comparable class adjustment. Users were also more likely to go out with girlfriends or boyfriends and to have deviant peer relations.

\section{Results of structural equation model analysis}

Table 3 shows the measure model coefficients indicating that the latent variables adequately represented the two observed variables constituting them.

Table 4 shows the estimated standardized path coefficients for the best model. The CFI and NNFI each exceeded 0.9 , and the RMSEA was lower than 0.05 . The results of goodness of fit $\left(x_{(68)}^{2}=81.1121\right.$, $p=0.13$ ) was non-significant, indicating a good fit.

As can be seen, substance use was predicted by perceptions of poor family relationships, and deviant peer relationships. Deviant peer relationships were in turn best predicted by frequent contact with peers and friends of the opposite sex along with less satisfaction with school performance. Those who had frequent peer contact outside of school tended to see their family relationships as weak. Adolescents who were satisfied with their school performance showed motivation and effort to study and good school adjustment. In summary, substance use was negatively related to family cohesion and positively related to deviant peer relations. School variables were not directly related to substance use but were indirectly related via family and peer relations.

\section{Discussion}

We found two main pathways associated with substance use in adolescents. Family and school connections were protective; peer relationships and especially deviant peer relations were risk factors.

Students who had strong family relationships were less likely to use substances and to be part of a strong peer group. They were more likely to have high academic expectations and to study hard. So in Taiwan, the family was protective against substance use by keeping adolescents occupied with family and school activities. A strong family connection was incompatible with strong peer relations, even relations that were not deviant. However, although 
Table 3

Measurement models relating observed with latent variables

\begin{tabular}{|c|c|c|c|}
\hline Variable & Regression coefficient & $t$-test & $p$-value \\
\hline \multicolumn{4}{|l|}{ 1. Family } \\
\hline (1) Family bond $\left(V_{0}\right)$ & 1.21 & 2.55 & 0.01 \\
\hline (2) Intimate relationship between parents $\left(V_{1}\right)$ & 1.00 & - & - \\
\hline \multicolumn{4}{|l|}{ 2. Motivation and effort to study } \\
\hline (1) Expectation of pursuing academic degree $\left(V_{2}\right)$ & 0.45 & 8.20 & $<0.0001$ \\
\hline (2) Time spent on study after class $\left(V_{3}\right)$ & 1.00 & - & - \\
\hline \multicolumn{4}{|l|}{ 3. School adjustment } \\
\hline (1) Class adjustment $\left(V_{4}\right)$ & 1.00 & - & - \\
\hline (2) Teacher support $\left(V_{5}\right)$ & 2.99 & 1.34 & 0.18 \\
\hline \multicolumn{4}{|l|}{ 4. Satisfaction with performance at school } \\
\hline (1) Satisfaction with academic performance $\left(V_{6}\right)$ & 2.17 & 2.89 & 0.004 \\
\hline (2) Satisfaction with other relevant curriculums $\left(V_{7}\right)$ & 1.0000 & - & - \\
\hline \multicolumn{4}{|l|}{ 5. Peer relationship } \\
\hline (1) Peer association $\left(V_{8}\right)$ & 9.96 & 9.34 & $<0.0001$ \\
\hline (2) Girlfriend/boyfriend association $\left(V_{9}\right)$ & 1.00 & - & - \\
\hline \multicolumn{4}{|l|}{ 6. Deviant peer behaviour } \\
\hline (1) Deviant behaviour at school $\left(V_{10}\right)$ & 0.49 & 10.87 & $<0.0001$ \\
\hline (2) Harmful behaviour $\left(V_{11}\right)$ & 1.00 & - & - \\
\hline \multicolumn{4}{|l|}{ 7. Substance Use } \\
\hline (1) Tobacco and/or alcohol use $\left(V_{12}\right)$ & 4.68 & 7.23 & $<0.0001$ \\
\hline (2) Betel nut use $\left(V_{13}\right)$ & 1.00 & - & - \\
\hline
\end{tabular}

Table 4

Standardized path coefficients for relations among latent variables

\begin{tabular}{lcr}
\hline Dependent variable/independent variable & Standardized regression coefficient & $t$-test \\
\hline 1. Substance use & & $p$-value \\
$\quad$ (1) Deviant peer behaviour & 0.40 & 2.55 \\
$\quad$ (2) Family cohesion & -0.44 & -2.05 \\
2. Deviant peer behaviour & -0.17 & -1.94 \\
$\quad$ (1) Satisfaction with performance at school & 0.88 & 8.2413 \\
$\quad$ (2) Peer relationship & & 0.01 \\
3. Peer relationship & -0.79 & -2.82 \\
$\quad$ (1) Family cohesion & & 0.0001 \\
4. Satisfaction with performance at school & 0.40 & 0.005 \\
$\quad$ (1) Motivation and effort to study & 0.50 & 2.52 \\
$\quad$ (2) School adjustment & & 1.76 \\
5. Motivation and effort to study & 0.93 & 0.01 \\
$\quad$ (1) Family cohesion & & 0.08 \\
\hline
\end{tabular}

school orientation was associated with a strong family bond, school variables were themselves only weakly related to the peer variables. In this respect, we found that deviant peer relations were inversely connected to satisfaction with school performance. Yet, non-deviant peer relations were unrelated to school orientation. Deviant peer relations, as expected, were associated with substance use.

These findings are compatible with those of Bogenschneider, Wu, Raffaelli, and Tsay (1998) who found that higher levels of responsiveness, such as family affection reported from mothers, were 
associated with a lower orientation to peers, which in turn resulted in lower rates of self-reported adolescent substance use. As found by Whitebeck (1999), satisfaction with performance at school was largely affected by family factors. In Taiwan, the family may affect school performance by instilling the need to put effort into school work. Findings are also consistent with those who emphasize the centrality of family process on adolescents' affiliation with deviant peers and subsequent deviant behaviour (Caspi et al., 1989; Moffitt, 1997; Patterson, 1982; Whitebeck, 1999).

There are two major limitations in this study. One is that the study was cross-sectional and so causal inferences are not possible. The second is that all family, school and peer variables were self-reported and unstandardized. Their validity is unknown. Nonetheless, the findings show interesting similarities and differences with published research from other countries and so should be pursued.

\section{References}

American Psychiatric Association. (1987). The diagnostic and statistical manual of psychiatric diagnoses (3rd ed., rev). Washington, DC: APA.

Ary, D. V., Duncan, T. E., Duncan, S. C., \& Hops, H. (1999). Adolescent problem behavior: The influence of parents and peers. Behaviour Research and Therapy, 37, 217-230.

Bahr, S. J., Hoffmann, J. P., \& Yang, X. (2005). Parental and peer influences on the risk of adolescent drug use. The Journal of Primary Prevention, 26(6), 529-551.

Beal, A. C., Ausiello, J., \& Perrin, J. M. (2001). Social influences on health-risk behaviors among minority middle school students. Journal of Adolescent Health, 28(6), 474-480.

Bogenschneider, K., Wu, M. Y., Raffaelli, M., \& Tsay, J. C. (1998). Other teens drink, but not my kid: Does parental awareness of adolescent alcohol use protect adolescents from risky consequences? Journal of Marriage and the Family, 60, 356-373.

Botvin, G. J., Malgady, R. G., Griffin, K. W., Scheier, L. M., \& Epstein, J. A. (1998). Alcohol and marijuana use among rural youth: Interaction of social and intrapersonal influences. Addictive Behaviors, 23(3), 379-387.

Bronfenbrenner, U. (1977). Toward an experimental ecology of human development. American Psychologist, 513-531.

Bronfenbrenner, U. (1979). The ecology of human development. Cambridge, MA: Harvard University Press.
Callas, P. W., Flynn, B. S., \& Worden, J. K. (2004). Potentially modifiable psychosocial factors associated with alcohol use during early adolescence. Addictive Behaviors, 29, 1503-1515.

Caspi, A., Bem, D., \& Elder, G. (1989). Continuities and consequences of interactional styles across the life course. Journal of Personality, 57, 375-406.

Chong, M. Y., Chan, K. W., \& Cheng, A. T. A. (1999). Substance use disorders among adolescents in Taiwan: Prevalence, sociodemographic correlates and psychiatric co-morbidity. Psychological Medicine, 29, 1387-1396.

Hops, H., Davis, B., \& Lewin, L. M. (1999). The development of alcohol and other substance use: A gender study of family and peer context. Journal of Studies on Alcohol Supplement, 13, 22-31.

Moffitt, T. (1997). Adolescence-limited and life-course-persistent offending: A complimentary pair of developmental theories. In T. Thornberry (Ed.), Developmental theories of crime and delinquency (pp. 11-54). New Brunswick, NJ: Transaction Publishers.

Nash, S. G., McQueen, A., \& Bray, J. H. (2005). Pathways to adolescent alcohol use: Family environment, peer influence, and parental expectations. Journal of Adolescent Health, 37, 19-28.

Olds, R. S., \& Thombs, D. L. (2001). The relationship of adolescent perceptions of peer norms and parent involvement to cigarette and alcohol use. The Journal of School Health, 71(6), 223-228.

Orvaschel, H., Puig-Antich, J., Chambers, W., Tabrizi, M. A., \& Johnson, R. (1982). Retrospective assessment of prepubertal major depression with the Kiddie-SADS-e. Journal of the American Academy of Child Psychiatry, 21, 392-397.

Patterson, G. R. (1982). Coercive family processes. Eugene, OR: Castilia.

Puig-Antich, J., \& Chambers, W. (1978). The schedule for affective disorders \& schizophrenia for school age children (Kiddie-SADS). New York: New York State Psychiatric Institute.

Sutherland, I., \& Shepherd, J. P. (2001). Social dimensions of adolescent substance use. Addiction, 96(3), 445-458.

Swadi, H. (1999). Individual risk factors for adolescent substance use. Drug and Alcohol Dependence, 55, 209-224.

Tot, S., Yzaici, K., Yazici, A., Metin, O., Bal, N., \& Erdem, P. (2004). Psychosocial correlates of substance use among adolescents in Mersin, Turkey. Public Health, 118, 588-593.

Weinberg, N. Z., Rahdert, E., Colliver, J. D., \& Glantz, M. D. (1998). Adolescent substance abuse: A review of the past 10 years. Journal of the American Academy of Child and Adolescent Psychiatry, 37, 252-261.

Whitebeck, L. B. (1999). Primary socialization theory: It all begins with the family. Substance Use \& Misuse, 34, 1025-1032.

Wright, D. R., \& Fitzpatrick, K. M. (2004). Psychosocial correlates of substance use behaviors among African American youth. Adolescence, 39(156), 653-667. 